\title{
AMP-HOUR COUNTING CHARGE CONTROL FOR PHOTOVOLTAIC HYBRID POWER SYSTEMS
}

\author{
Thomas D. Hund \\ Sandia National Laboratories \\ PO Box 5800 \\ Albuquerque, New Mexico 87185-0753
}

\author{
Bruce Thompson \\ Biri Systems \\ 30 Sodom Rd. \\ Ithaca, NY 14850
}

\begin{abstract}
An amp-hour counting battery charge control algorithm has been defined and tested using the Digital Solar Technologies MPR-9400 microprocessor based photovoltaic hybrid charge controller. This work included extensive laboratory and field testing of the charge algorithm on vented lead-antimony and valve regulated lead-acid batteries. The test results have shown that with proper setup amp-hour counting charge control is more effective than conventional voltage regulated sub-array shedding in returning the lead-acid battery to a high state of charge.
\end{abstract}

\section{INTRODUCTION}

Batteries in stand-alone and PV hybrid systems are commonly subject to abusive conditions that are generally due to, 1) under charging in low resource periods, 2) excessive charging in high resource periods, and 3 ) inappropriate or ineffective charge control for the battery technology. The individual or combined effects of resource changes, poor charge control, and the daily load changes can be potentially damaging to the battery. Previously available PV charge controllers or charge control strategies such as on/off PV array shedding will generally provide the battery with sufficient charging current to complete the bulk charge phase which will return the battery to 80 to $95 \%$ state of charge (SOC) $[1,2]$. After the bulk charge phase, the taper or absorption charge phase is very important in preventing stratification, hard sulfation, and premature capacity loss. If a regulation voltage of 2.35 to $2.40 \mathrm{vpc}$ is used for charging vented lead-antimony batteries, then a 10 to 24 -hr regulated voltage finish charge period is usually required. The available time for battery finish charging in PV systems is generally much less than 10-hrs. The short time at regulation voltage results in an incomplete finish charge phase which consistently leaves the battery in an under charged condition. If the regulation voltage for vented lead-antimony batteries is raised to 2.45 to $2.50 \mathrm{vpc}$ and the reconnect voltage is raised to 2.28 to $2.30 \mathrm{vpc}$, then the finish charge time period can be significantly reduced. With the higher regulation voltage, the battery may then be subject to excessive charge in high resource periods or low load periods. The primary effect of the higher regulation voltage without amp-hour counting charge control on vented batteries is the dramatically increased watering requirements and increased erosion of active plate material. For VRLA batteries the regulation voltage should be set to the manufacturers recommended value for a cycling application. VRLA battery cycling regulation voltage is usually 2.35 or $2.40 \mathrm{vpc}$. A reconnect voltage of 2.28 to $2.30 \mathrm{vpc}$ is also very important to complete the finish charge period. Very little can be done to accelerate the finish charge period for VRLA batteries because their charge acceptance is limited by the oxygen recombination cycle [3]. Higher regulation voltages will only accelerate dry-out. That is why it is so very important to use constant voltage charging for the finish charge phase or simulate it with a well designed PV array shedding strategy.

Based on energy calculations from the "RAPS Design Manual", published by the University of Cape Town South Africa and the author's own calculations, battery energy costs for PV hybrid systems are estimated to be about $\$ 0.35$ to $\$ 1.00 / \mathrm{kWh}$ over the life of the system $[4,5]$. As indicated above, any degradation in battery cycle-life can result in a significant system cost increase. The potential cost benefit to stand-alone and PV hybrid systems is substantial if batteries meet their rated cycle-life.

Amp-hour (Ah) counting charge control for PV hybrid battery charging systems is new to this application, but in the Battery Technical Manual from Battery Council International the cycle-life test procedure for deep cycle marine/RV batteries does use Ah counting as a means to ensure the battery is at a high SOC [6]. In this test procedure the maximum and minimum values for percent overcharge per cycle for vented and VRLA batteries are specified. This along with regulation voltage insures complete battery recharge.

Maximizing battery cycle-life requires using the manufacturers recommended regulation voltages, appropriate system design, effective charge control, and reaching the recommended overcharge in $A h$ when the battery receives a full recharge. The excess Ah are a way to compensate for battery efficiency losses. For most vented lead-antimony batteries the recommended Ah overcharge is between 120 and $130 \%$ of the discharged Ah. VRLA batteries, which require more time at regulation voltage, are much more efficient and only require between 105 and $115 \%$ of the discharged Ah. This paper will evaluate an Ah counting charge control algorithm for PV hybrid systems using a microprocessor based charge controller.

This work is supported by the Photovoltaic Energy Technology Division, US Department of Energy.

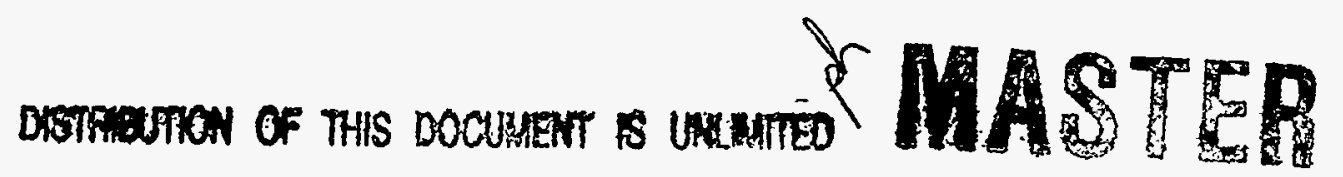

Sandia is a multiprogram laboratory operated by Sandia Corporation, a Lockheed Martin Company. for the United States Department of Energy under contract DE-AC04-94AL85000. 


\section{DISCLAIMER}

This report was prepared as an account of work sponsored by an agency of the United States Government. Neither the United States Government nor any agency thereof, nor any of their employees, make any warranty, express or implied, or assumes any legal liability or responsibility for the accuracy, completeness, or usefulness of any information, apparatus, product, or process disclosed, or represents that its use would not infringe privately owned rights. Reference herein to any specific commercial product, process, or service by trade name, trademark, manufacturer, or otherwise does not necessarily constitute or imply its endorsement, recommendation, or favoring by the United States Government or any agency thereof. The views and opinions of authors expressed herein do not necessarily state or reflect those of the United States Government or any agency thereof. 


\section{DISCLAMIER}

Portions of this document may be illegible in electronic image products. Images are produced from the best available original document. 


\section{AH COUNTING CHARGE CONTROL}

In a cooperative effort with Digital Solar Technologies a microprocessor based Ah counting charge control algorithm was defined and tested using the MPR-9400 PV hybrid charge controller. The controller under test uses staged PV sub-array switching to achieve a taper charge for the battery finish charge period. This charge control method can be a very effective charge strategy if properly setup. It is typically used in medium to large PV hybrid systems.

The new Ah counting charge control algorithm calculates battery Ah for each complete cycle. A new cycle is started when the battery reaches the predetermined overcharge in Ah. To implement the new Ah counting charge algorithm required four new input variables. These variables are:

1) BATAHINIT - Estimated battery capacity in Ah (Input by user),

2) AHVRESET - Battery voltage when battery charging or high voltage disconnects (HVD's) are reactivated (Input by user),

3) \%ADD - Deficit or excess battery Ah at initial battery regulation voltage (Input by user - +or-25\%),

4) \%OVER - Maximum overcharge above the daily Ah DOD (Input by user - 0 to $99 \%$ ).

The Ah counting charge control algorithm opens the high voltage disconnect relays (HVD 1 and 2) when the specified \%OVER plus \%ADD Ah are charged into the battery. The \%OVER and \%ADD Ah begin counting when the first HVD is reached. Before the specified overcharge is reached, HVD 1 and 2 will operate as indicated by the preset disconnect and reconnect voltages. The \%OVER value is defined in equation 1.

\section{((Ah chr - Ah dischr) / Ah dischr) x 100}

Ah calculations for battery SOC and \%ADD are based on the battery BATAHINIT capacity input by the user. The displayed battery capacity in Ah and battery $\%$ SOC are reset to the BATAHINIT and $100 \%$ values respectively when the required overcharge is reached, or at $6 \mathrm{PM}$ after an equalization charge. If a load is turned on after charging is terminated, then the PV array will be reconnected when the battery reaches the preset AHVRESET voltage.

\section{SETUP AND INITIALIZATION}

The MPR-9400 initialization for Ah counting charge control requires the user to identify the additional variables from the previous section. The HVD 1 and 2 regulation voltage is generally available from the battery manufacturer and the reconnect voltage is usually set based on the sub-array shedding sequence and system design. The \%OVER, and BATAHINIT values are available from the battery manufacturer. The \%ADD parameter is very system dependent and can only be accurately identified by:

1) equalizing or boost charging the batteries,
2) resetting BATAHINIT

3) running a standard cycle to regulation voltage,

4) recording the battery Ah when regulation voltage is reached, and

5) calculating \%ADD by equation 2 .

\section{((BATAHINIT - Bat Ah at Vr) / BATAHINIT) $\times 100$}

In most cases the \%ADD variable will be less than plus or minus $7 \%$. Test results have shown that as vented lead-antimony batteries age they will require adjusting the $\% A D D$ parameter from a positive number to less than $7 \%$. This is because of the increased gassing current resulting from antimony poisoning [7]. VRLA batteries typically will not experience significant changes in the $\% A D D$ value over their life because they generally have a stable end of charge current with very low gassing current.

\section{PV SYSTEM SIMULATOR TEST RESULTS}

The measured percent overcharge from three different stand-alone PV system simulations and a PV hybrid simulation has been obtained using an automated PV hybrid system tester from Team Specialty Products in Albuquerque. This test-bed is capable of simulating two PV arrays or one PV array and one engine generator with two loads. All system parameters are fully programmable and automated.

\section{Stand-Alone PV System Simulation}

The stand-alone PV system test was conducted to evaluate Ah counting charge control using an array Ah to load $A h(C: L)$ ratio of $1.5,1.75$, and 2.0 . The simulation was configured to duplicate a typical stand-alone PV system using two 7-amp PV sub-arrays for battery charging. The battery used in the system simulation was a GNB 12-5000X 400 Ah VRLA battery. This battery is very similar to the GNB Absolyte IIP which is commonly used in larger stand-alone and PV hybrid systems. A 1.5-amp continuous load and an adjustable nighttime load was used to establish the three different $C: L$ ratios. The new $A h$ counting charge control parameters for the MPR-9400 were input based on battery manufacturers specifications and the \%ADD calculation from the above initialization cycle. See Table 1 for a complete list of system parameters.

In Fig. 1 are the test results, which show that the Ah counting charge control algorithm limits battery overcharge to within the 105 to $110 \%$ specified by GNB. The voltage regulated charge period is also maintained between 1.9 and 2.3-hrs. Using the same regulation voltages and system configuration without Ah counting charge control resulted in a battery overcharge range between 114 and $128 \%$. The voltage regulated charge period also varied between 3.9 and 5.0-hrs depending on the $\mathrm{C}: \mathrm{L}$ ratio. Without Ah counting charge control the only way to reduce overcharge is to lower regulation voltage or provide a two stage voltage regulated charge control. The lower regulation voltage and two-stage charge control will decrease overcharge, but it will also increase the time required to charge the battery. Voltage regulated charge 
control alone makes it very difficult to obtain optimum recharge due to weather and system design.

\begin{tabular}{|l|l|}
\hline System & \multicolumn{1}{|c|}{ Value } \\
\hline Sub-Array 1 & 7-amp peak \\
Sub-Array 2 & 7-amp peak \\
Load 1 & Continuous 1.5-amps \\
Load 2 & $19.3,15.3, \& 12.3$-amps \\
Battery Size & $400 \mathrm{Ah}$ \\
Battery DOD & $13.5,12.0, \& 10.5 \%$ \\
C:L Ratio & $1.5,1.75, \& 2.0$ \\
\hline MPR-9400 & $\mid$ \\
\hline HVD-1 & $2.36 \mathrm{vpc} \mathrm{Vr} \mathrm{2.30} \mathrm{vpc} \mathrm{Vrr}$ \\
HVD-2 & $2.35 \mathrm{vpc} \mathrm{Vr} \mathrm{2.29} \mathrm{vpc} \mathrm{Vrr}$ \\
Temp. Comp. & $(-5 \mathrm{mv} / \mathrm{C} / \mathrm{cell})$ \\
BATAHINIT & $400 \mathrm{Ah}$ \\
AHVRESET & $2.08 \mathrm{vpc}$ \\
\%ADD & 1.9 \\
$\%$ OVER & 7 \\
\hline
\end{tabular}

Table 1. PV system simulator and charge controller setup parameters.

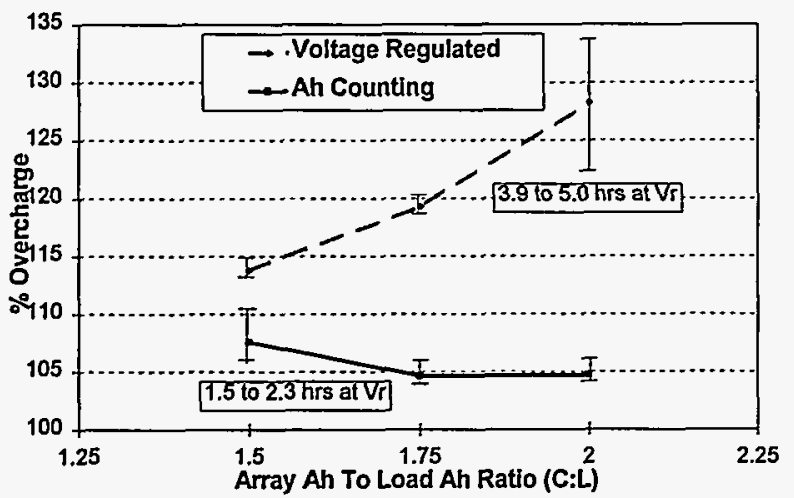

Fig. 1. VRLA battery \% overcharge with and without $A h$ counting charge control.

\section{PV Hybrid Simulation}

The PV hybrid simulation was designed with one 7amp PV array and an engine generator set to charge the battery at 20 -amps once the 12.1 volt engine start voltage was reached. The Charge Controller was programmed to terminate all charging when the required $107 \%$ overcharge was reached. The system $C: L$ ratio with one $P V$ array was 0.62 and the \%ADD input variable was still +1.9. This system design resulted in the battery discharging to 12.1 volts during the fourth cycle. The engine generator then returned the battery to full charge after the fourth cycle.

In Fig. 2 are the battery Ah and voltage plotted over a ten cycle period. The measured overcharge values after the engine generator battery recharge were 110 and $111 \%$. The results indicate good reproducibility and they are close to the desired value of $107 \%$. This test is also useful in identifying the effects of different $P V$ array $C: L$ ratios and engine generator control strategies. In this case the generator ran for a total of 3.5-hrs in bulk charge mode and 7.2-hrs in finish or taper charge mode for a total run time of 10.7 -hrs returning 152 Ah back into the battery. The end of charge current, which can be used to terminate charging, was measured at 3.9-amps.

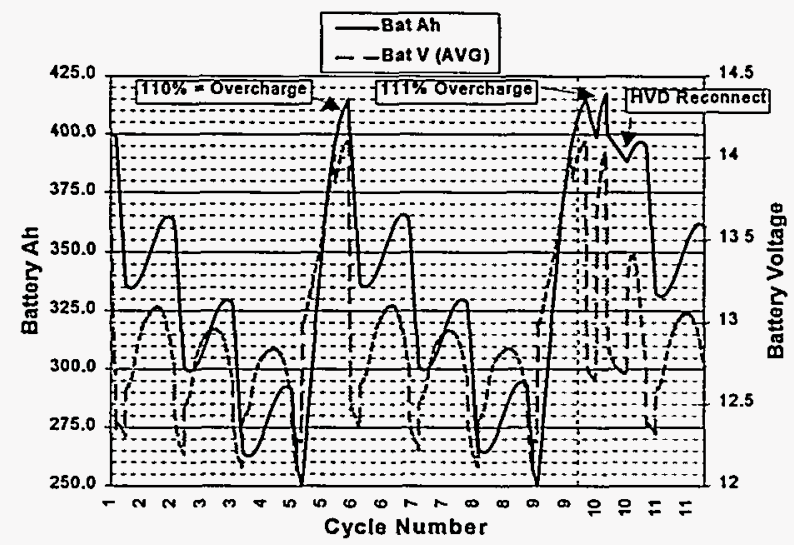

Fig. 2. PV hybrid simulation using Ah counting charge control.

\section{FIELD TEST RESULTS}

In addition to the laboratory testing, the Ah counting charge control algorithm was used on two stand-alone PV systems with a 700 Ah Trojan L-16 vented lead-antimony battery and a 400 Ah GNB 12-5000X VRLA AGM battery. These system tests represent each lead-acid battery technology and demonstrated that the Ah counting charge control algorithm will function well with each battery type even though they are significantly different in their recharge characteristics. The most significant difference between the two battery types is the battery Ah at initial regulation voltage. This charging difference is compensated for by the \%ADD parameter in the MPR9400.

\section{Ah Charge Control Using Trojan L-16 Batteries}

The stand-alone PV system using Trojan L-16 batteries is configured with three PV sub-arrays charging at a peak current of 16,10, and 4-amps. The two higher current sub-arrays are switched with the MPR-9400 charge controller and the 4-amp array is permanently connected to the battery bank. The load is variable and is operational day or night. Daily loads average $70 \mathrm{Ah} /$ day but can range between 10 and $200 \mathrm{Ah} /$ day. The voltage setpoints on the MPR-9400 are set for staged sub-array switching at:

$H V D-1=2.45 \mathrm{vpc} V r$ and $2.29 \mathrm{vpc} \mathrm{Vrr}$, HVD-2 $=2.43 \mathrm{vpc} V \mathrm{r}$, and $2.27 \mathrm{vpc}$ Vrr.

The Ah counting program parameters are set to:

BATAHINIT $=300$ Ah

AHVRESET $=2.06 \mathrm{vpc}$

$\% A D D=-11.7$

$\%$ OVER $=30$

$\%$ OVER $(0.30 \times 70)+\%$ ADD $=-14.1 \mathrm{Ah}$

In Fig. 3 are the Ah overcharged and the respective percentage overcharge for a 15-day period. The results 
indicate that the Ah overcharged are between 15 and 59 Ah with an average of $31 \mathrm{Ah}$. The percent overcharge range is between 128 and $196 \%$ with an average of $153 \%$. These values are much larger and have a much wider range than would normally be seen in laboratory testing on new batteries. These batteries are 5-yrs old, and as a result of normal aging processes, have experienced an increase in their gassing currents. The higher gassing current requires more time for the battery to get to regulation voltage. This results in a necessary but greater than normal overcharge. Without Ah counting charge control, the Ah overcharged would be greater resulting in increased water loss and maintenance.

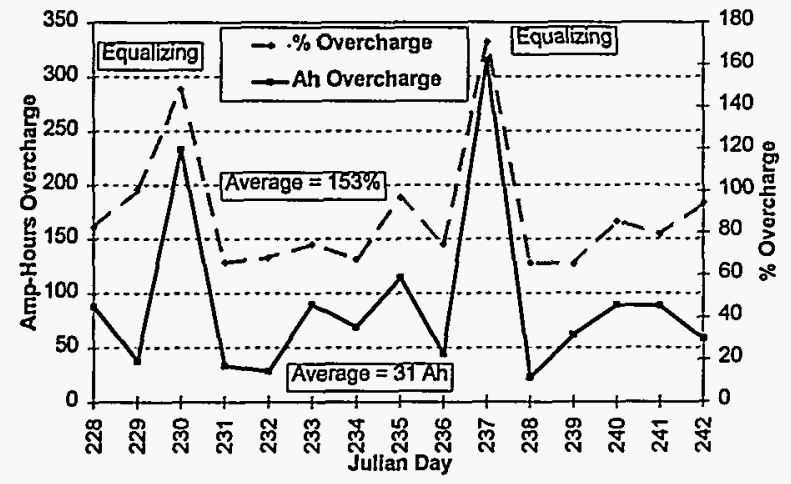

Fig. 3. Stand-alone PV system using Ah counting charge control and vented Trojan L-16 battery.

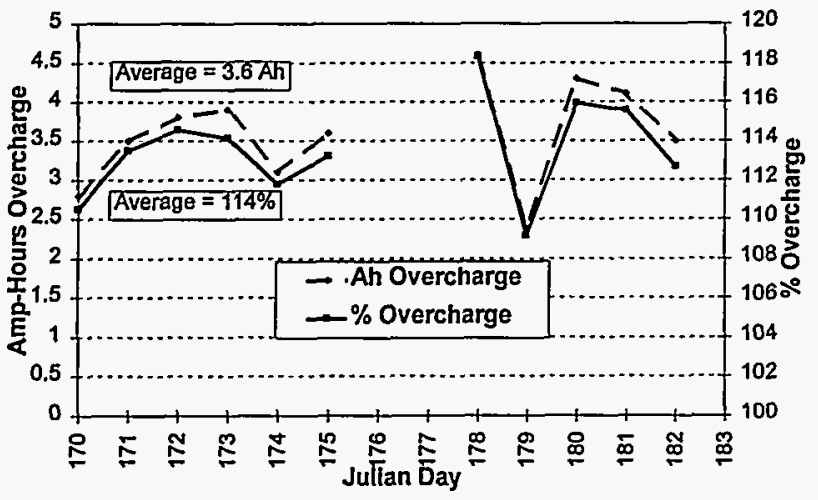

Fig. 4. Stand-alone PV system using Ah counting charge control and GNB 12-5000X VRLA AGM battery.

\section{Ah Charge Control Using GNB 12-5000X Batteries}

A second stand-alone PV system using GNB 12$5000 X$ VRLA AGM batteries is configured with two PV subarrays charging at a peak current of 7 -amps each. The two sub-arrays are switched with the MPR-9400 charge controller in a staged manner to simulate a taper finish charge. The load is continuous and averaged 1.1-amps for a total of $26 \mathrm{Ah} /$ day. The voltage setpoints on the MPR9400 were set for staged sub-array switching at:

$H V D-1=2.36 \mathrm{vpc} V r$ and $2.30 \mathrm{vpc} \mathrm{Vrr}$, $\mathrm{HVD}-2=2.35 \mathrm{vpc} \mathrm{Vr}$, and $2.29 \mathrm{vpc} \mathrm{Vrr}$.
The Ah counting program parameters are set to:

BATAHINIT $=250 \mathrm{Ah}$

AHVRESET $=2.04 \mathrm{vpc}$

$\% A D D=+3.5$

$\%$ OVER $=10$

\%OVER $(0.10 \times 26)+\% A D D=11.3 \mathrm{Ah}$

In Fig. 4 are the Ah overcharged and the respective percentage overcharge for an 11-day period. The results indicate that the Ah overcharged are between 2.4 and 4.6 Ah with an average of 3.6 Ah. The percent overcharge range is between 109 and $118 \%$ with an average of $114 \%$. These values are higher than the test results from the indoor system simulator and indicate that a slightly lower \%ADD value may be used. The data also shows than in an actual PV system Ah counting charge control will be slightly less stable due solar and weather variations.

\section{SUMMARY}

Test results using the MPR- 9400 Ah counting charge algorithm have shown that in typical stand-alone and hybrid PV systems Ah counting can improve battery charging over conventional voltage regulated sub-array switching by recharging the battery as quickly as possible without excessive overcharge during high resource or low load periods. Appropriate overcharge is necessary to compensate for battery efficiency losses, prevent electrolyte stratification, prevent hard sulfation, and minimize premature capacity loss. Excessive overcharge will accelerate dry-out in VRLA batteries and increase maintenance requirements for flooded/vented batteries. Therefor, maintaining appropriate overcharge levels can improve battery cycle-life, lower maintenance costs, and reduce $P V$ system life-cycle costs.

\section{REFERENCES}

[1] Woodworth, J.R., Harrington, S.R., Dunlop, J.D., et al, "Evaluation of the Batteries and Charge Controllers in Small Stand-alone Photovoltaic Systems", First World Conference on Photovoltaic Energy Conversion, Hawaii, Dec. 1994.

[2] G.W. Vinal, Storage Batteries, John Wiley \& Sons, 1951, ISBN 471908169, pp.240-271.

[3] M.L. Whitehead, "FAILURE MECHANISMS IN VRLA BATTERIES", Proc. Of $8^{\text {th }}$ Battery Conference and Exhibition, Solihull, UK, May 1994.

[4] University of Cape Town Energy for Development Research Centre, Remote Area Power Supply (RAPS) Design Manual, ISBN:0 79921435 3, Ph. (021) 650-3230, Sept. 1992.

[5] T.D. Hund, "Flooded Lead-Acid Battery Costs Vs. Valve Regulated Lead-Acid Battery Costs", Internal Sandia Report, Aug.1997.

[6] Battery Council International, Battery Technical Manual $2^{\text {nd }}$ Edition, 401 North Michigan Av. Chicago, Illinois 60611, (312) 6446610.

[7] J.L. Dawson, M.I. Gillibrand, and J. Wilkinson, "THE CHEMICAL ROLE OF ANTIMONY IN THE LEAD-ACID BATTERY", Power Sources 3, 1971, pp.1-11. 